\title{
Engineering and Social Justice through an Accreditation Lens: Expectations and Learning Opportunities for Ethics and Equity
}

\author{
K Haralampides ${ }^{\dagger}$, D MacIsaact $+\dagger$, C Diduch ${ }^{\dagger}, B$ Wilson ${ }^{\dagger}$ \\ tFaculty of Engineering, ${ }^{+}$Center for Enhanced Teaching and Learning, University of New Brunswick \\ katy@unb.ca
}

\begin{abstract}
The inclusion of Ethics and Equity as one of the twelve essential attributes mandated for accredited engineering programs in Canada represents a unique opportunity for engineering educators. Never before has the term equity been included in criteria for accreditation. To apply professional equity in the practice of engineering requires our students to learn about world affairs and diverse ways of life, about historical and sociological frameworks for exploring their own global frames of reference, and those of others, about current and historical examples of engineering approaches to making our world more equitable, and about how all of this can be used to integrate equity into their practice of engineering. Three settings in which we can provide our students with opportunities to learn about these concepts include humanities courses, an engineering equity core course, and immersion throughout coursework in engineering core courses. Ideally, a combination of the three should be implemented.
\end{abstract}

Keywords: $\mathrm{CEAB}$ attributes, ethics and equity, fairness and sustainability.

\section{INTRODUCTION}

The inclusion of Ethics and Equity as one of the twelve graduate attributes mandated for accredited engineering programs in Canada [1] represents a unique opportunity for engineering educators. Never before has the term equity been included in criteria for accreditation. While most accreditation systems have for many years included criteria auxiliary to equity, their focus has been on professionalism, ethics, and the impact of technology on society and these criteria alone are not sufficiently comprehensive to embed issues of equity into engineering education.

The Canadian Engineering Accreditation Board (CEAB) describes the tenth graduate attribute as [1]:

- Ethics and Equity: An ability to apply professional ethics, accountability, and equity.
It is now up to us, as engineering educators, to detail what it means to "apply professional...equity", and develop ways to help our students to acquire this attribute. Equity is basically the quality of being fair. At an apparent level, applying professional equity requires engineers to uphold the policies and guiding principles outlined in employment equity legislation and workplace diversity management programs [2] in Canada, aimed at removing inequalities in the workplace, and ensuring a workforce that reflects the communities that they serve [3]. This is indeed an important application of equity, and we should develop in our students the knowledge and skills they need to apply professional equity in this way.

For engineers however, applying professional equity spans beyond equity within our own workplaces, since the work that we conduct can have profound influence on far reaching communities. In her book titled The Real World of Technology [4], Ursula Franklin describes engineering as a discipline in which the 'bookkeeping' should be conducted with three sets of books - one for economy, one for people and social impacts, and one for environmental accounting. If we are, as Franklin suggests, to consider social impact, and be accountable to people and the environment in our work as engineers, then we must teach our students to promote development and designs that support fair and sustainable treatment of the people and natural environments affected by them. That is, we must teach our students to include the application of equity as an inherent component in their engineering practice. The purpose of this paper is to suggest a foundation for achieving this.

\section{EXPECTATIONS FOR DEMONSTRATING THE ABILITY TO APPLY EQUITY}

Being able to establish global frames of reference is critical to applying equity and is therefore a good place to start articulating expectations for demonstrating the ability to apply equity. People can be 'positioned' in our world within a frame made up of many axes such as race, gender, age, sexual orientation, religion, wealth, ability, education, politics, culture, geography etc. A person's position within this framework characterizes their global 
frame of reference, and this frame of reference influences the way they may be affected by an engineering decision. Consider engineering practices that have led to our current predicament involving climate change. Compared to Canadians, those in developing countries such as Sierra Leone have more "systemic vulnerabilities to climate change, due to their more limited adaptive capacities" [5]. Even comparing frames of reference within Canada though, there are populations that are more vulnerable than others. Health Canada has identified peoples in northern communities, as well as seniors, children and infants, socially disadvantaged individuals, and those with pre-existing medical conditions as most susceptible to the predicted impacts [5].

Frames of reference not only influence the impact that engineering decisions have on people; they also influence how people make decisions. We all view the world from our own frame of reference and without ability and concerted effort to take into consideration perspectives from differing frames of reference, our decisions are generally made based on our own perspective which often overlooks important considerations. Consider engineering practices that led to the installation of a merry-go-round style water pump, the PlayPump ${ }^{\circledR}$, which was designed to ease the burden of water retrieval for women in communities across southern Africa by harnessing the energy generated as children played on playground equipment. The concept was initiated by engineers outside the communities who were genuinely interested in improving living conditions for communities. While the pump and reservoir system worked well in trials with many children energetically playing, cultural aspects of the design were not fully considered by the engineers. In the approximately 1800 communities where a PlayPump ${ }^{\circledR}$ was installed, the children simply did not play on the tiring merry-go-round leaving the women with the arduous task of spinning the heavy wheel. PlayPumps ${ }^{\circledR}$ are no longer considered a viable technology for retrieving water in these communities, and many have been replaced with a hand pump [6]. While well intended, the engineering team responsible for implementing the PlayPumps ${ }^{\circledR}$ used their own point of reference for play culture in designing their solution for improved water access, and this prevented them from being able to improve living conditions in the communities they were trying to help.

If we want our students to be able to evaluate whether or not their design and development decisions are fair and sustainable, they must be able to consider their decisions from the various frames of reference representing the people who may be affected. They must also be able to consider how their own frame of reference may be influencing their decisions. Thus we should expect our graduating students to be able to:
1. Identify the various axes which define a global frame of reference

2. Characterize their own global frame of reference, and that of others

3. Explain how the different dimensions of a global frame of reference interact to influence the consequences of engineering decisions on communities

4. Explain how the different dimensions of a global frame of reference interact to influence how engineering decisions are made

Knowledge feeds the abilities described above. The more our students know about world affairs and diverse ways of life, the richer their characterizations of varying frames of reference can become. The more they know about how the axes and their interactions developed historically, the more reasoning they can do about their influences. To harvest this knowledge however, they must also be able to examine it in the context of a sociological framework and use the results of their examination in their practice of engineering. Just as knowledge feeds the abilities described above, so does critical thought, especially when it is self-reflective because this forces students to put their assumptions in check. Once students are able to reason this deeply about the things that need to be considered when making an engineering decision, they are ready to apply equity in their engineering practice. Behaviours, which demonstrate that students are at this level, include the ability to:

5. deconstruct current and historical approaches to global and local engineering challenges (e.g. climate change, energy production, consumption, and distribution, housing, electronic information access...) to ascertain elements of fairness and sustainability

6. examine engineering design challenges to ascertain elements of fairness and sustainability and make informed choices which reflect these characteristics in their design.

\section{OPPORTUNITIES TO LEARN ABOUT EQUITY}

The CEAB has placed high expectations on our programs by including Ethics and Equity as one of the twelve graduating attributes. As highlighted by the six abilities listed above, being able to apply professional equity in the practice of engineering requires our students to learn about world affairs and diverse ways of life, about historical and sociological frameworks for exploring their own global frames of reference, and those of others, about current and historical examples of engineering approaches to making our world more 
equitable, and about how all of this can be used to integrate equity into their practice of engineering.

There are three useful settings in which we can provide our students with opportunities to learn about these concepts: 1) in complementary studies courses taught by colleagues in humanities, 2) in an engineering core course dedicated to teaching concepts of equity, and 3) immersed throughout coursework in engineering core courses. Ideally, a combination of the three should be implemented.

It is important for our students to learn about equity from experts such as sociologists, as they are well positioned to provide the knowledge base and frameworks for thinking about concepts of equity. They also offer opportunities for students to broaden their university experience, thereby indirectly expanding their frame of reference. We need to continue to work alongside our colleagues in humanities; however we should not rely on them solely to deliver the learning opportunities our students need to develop their ability to apply equity in their practice of engineering. The common engineering education model that groups all non-technical content together as complementary studies and outsources its delivery does not facilitate appropriate opportunities for our students to learn about equity. This model conceptually segregates it from other engineering content, making it difficult for students to learn how to integrate it into their engineering practice. The model also gives the impression to students, counter to what is mandated by the $\mathrm{CEAB}$, that learning about equity is supplemental to their engineering education.

One way to continue to work with experts in humanities while helping our students to better integrate what they are learning about equity is by teaming with our colleagues to offer an engineering course focused on equity in the context of engineering. It could be a course that includes other professional engineering content such as law and/or ethics. By making this course part of the engineering core, we can also demonstrate to our students the value we place on equity in our engineering practice, and in so doing, encourage them to as well.

An even stronger demonstration of the value that we place on equity in our engineering practice is to implement an immersion-based approach to teaching it, which embeds opportunities to learn about equity into the engineering science and design coursework that we already teach. The following examples delineate some suggestions about how to do this, categorized by the abilities they foster:

\subsection{Exploring Global Frames of Reference (abilities 1-4)}

Often, simple computational questions that we regularly use to teach our students technical content can be easily tweaked to include opportunities to learn about world affairs and diverse ways of living. The question below exemplifies how a simple circuit analysis question can be rewritten to inform students that there is a wind farm supplying power to the community of Amherst, Nova Scotia.

Example - a question in an $1^{\text {st }}$ year electrical course: The voltage divider depicted in the figure (not included) is used as part of a control circuit for a wind turbine that is part of the Amherst Wind Farm. Find the voltage labeled.

Sometimes reformulating the context of a question can convey even richer information, possibly leading students to further reading, as exemplified below:

Example-a question in a $2^{\text {nd }}$ year statistics course: Worldwide, about $40 \%$ of the total population is deficient in iron, often severely enough to cause anemia [7]. A random sample of 272 people living in the Upper East region of Ghana in 2003 yielded 139 deficient in iron [8]. Do these data suggest that the true proportion for this region in 2003 differs from the previous worldwide proportion? Test the relevant hypothesis using $\alpha=0.05$.

Example - a problem posed in a $2^{\text {nd }}$ year fluids course: Using the water budget equation balancing the inflow, outflow, and storage, calculate the potential for flooding in the City of New Orleans for the given precipitation and outflow pumping data as well as geographic topography. In your role as a hydraulic engineer, comment on options for protection of the communities.

There are also many courses already poised for us to provide opportunities for our students to learn about global frames of reference in a way which complements learning of existing content. Mills' sociological framework is a tool that can be used to initiate development of such opportunities [9]. Central to his framework are three questions that can form the basis of assignments and discussions. They are:

- how is "_ " organized and what are the consequences of organizing it that way

- what is the history of this way of organizing

- who and what are coming to prevail as a result?

The examples below demonstrate how these questions can be used to create assignments or facilitate discussions that provide students with opportunities to explore frames of reference in the context of content also being addressed in more traditional ways in a course.

Example - an assignment in an engineering economics course: 
Choose an economic model. Describe how is it organized and why it is organized that way historically. Explain the consequences of its organization, and identify who is coming to prevail as a result.

Example - an open discussion in an upper level biomedical course:

Describe historically, advances made in prosthetics development. What are the factors promoting and inhibiting advancement? What groups of people would benefit most from further advancement in prosthetics development?

When activities like this are used to supplement what is being learned about equity in the other two settings, students should have ample opportunity to meet our expectations regarding their abilities to explore global frames of reference and their influence on equity.

\subsection{Deconstructing Engineering Approaches in terms of Equity (ability 5)}

Contextualizing questions can also provide students with opportunities to deconstruct current and historical examples of engineering solutions to elucidate their impact on promoting or inhibiting equity. For example, a modeling exercise can be used in an air quality course to concurrently assess the application of the technical material and the concepts of equity. 'Cancer Alley' refers to an area along the Mississippi River between Baton Rouge and New Orleans, Louisiana, which contains numerous industrial plants. There is anecdotal evidence of cancers near the industrial sites, though industry leaders and state officials say Cancer Alley is a myth [10]. Students could be asked to conduct a modelling exercise and to produce plots of concentration of contamination as a function of various wind speeds and atmospheric stability conditions for distances varying from the base of an industrial stack to $1 \mathrm{~km}$ downstream. Students could also be asked to prepare a reflective essay deconstructing the topic of environmental racism in the downstream communities.

Group projects involving case studies and/or issue analysis also work well to provide opportunities for students to report on current and historical examples of engineering approaches to making our world more equitable. Students could, for example, work in pairs in a $3^{\text {rd }}$ year electrical power system course to report on the advantages and disadvantages of various energy production techniques, based on case studies within different frames of reference. Written reports and/or presentations are excellent reporting mechanisms, but so are short documentaries and posters, which may be more effective when time is a constraint, either for delivering, or grading the work. More example topics can be found in Swift et al [11].

\subsection{Examining Engineering Design Challenges (ability 6)}

The ability to examine engineering design challenges to ascertain elements of fairness and sustainability and make informed choices which reflect these characteristics is one that requires proficiency in the rest of the abilities to master. Nevertheless, it is as close as we can get in the classroom to applying professional equity and our students should not be made to wait until the upper years to start learning to do it. While they will need to be attentively directed when they first start, as they develop this skill along side the other abilities, their dependence on direction should decrease.

Courses that introduce students to engineering are well suited for the kind of directed examination necessary to help students learn how to integrate equity into their engineering practice. An intriguing example of the kind of learning activity that could be accommodated at this level is a team pin-up. Students are put into teams and given an open problem to solve. For example, teams could be asked to come up with one idea that engineers could implement to reduce poverty. Each team produces a solution in the form of a small poster. Before class, each team's solution is posted (pinned-up) so that everyone in the class has a chance to review all of the solutions and come up with three questions which help to critique the them. Then, during class, the questions are used as a means for guiding discussion during which students defend their solutions. At the end of the class, students can vote on a best solution. To ensure specific issues are addressed, instructors can also post a solution. According to team-based learning expert, Larry Michealsen [12], students do most of their learning during the discussion time, which can be considered to be essential feedback. If we guide our students through learning activities like the pin-up, then, by the time they get to their senior course, they will be poised to integrate concepts of equity into their capstone and other senior design projects.

\section{CONCLUSIONS}

It is encouraging to see equity recognized as a critical component in engineering education. For the first time, the $\mathrm{CEAB}$ criteria are finally recognizing the importance of all three of Franklin's 'books', though they have yet to clearly articulate their expectations for equity. We have taken liberty to offer more clarity on this attribute, and hope it helps educators to strengthen their programs. 


\section{Acknowledgements}

The authors would like to thank Jennie Hornosty and Susan Machum for providing the sociological backdrop for this paper.

\section{References}

[1] Canadian Accreditation Board, Accreditation Criteria and Procedures Report, 2011. Available as of May 08, 2012 from http://www.engineerscanada.ca/files/ w Accreditation Criteria Procedures 2011.pdf.

[2] Carol Agocs and Catherine Burr, "Employment equity, affirmative action and managing diversity: assessing the differences," International Journal of Manpower, 17(4/5), pp 30-45, 1996.

[3] Local Government Improvement and Development, Equality and diversity in the workplace, Available as of May 08, 2012 from http://www.idea.gov.uk/idk/core/ page.do?pageId=7345916.

[4] Ursula Franklin, The Real World of Technology, House of Anansi Press (1990).

[5] Canadian Medical Association, Available as of May 14, 2012 from http://policybase.cma.ca/dbtw-wpd/Policypdf/ PD10-07.pdf.
[6] Water for People, Available as of May 14, 2012 from http://www.waterforpeople.org/extras/playpumps/updateon-playpumps.html.

[7] R.M. Welch and R.D. Graham. "A new paradigm for world agriculture: meeting human needs" Field Crops Research 60, 1-10, 1999.

[8] Ghana Statistical Service (GSS), Ghana Health Service (GHS), and ICF Macro. Ghana Demographic and Health Survey 2008: Key Findings. Calverton, Maryland, USA: GSS, GHS, and ICF Macro. 2009.

[9] C. Wright Mills, The Sociological Imagination. Oxford University Press, 256 pages, (1959).

[10] Donna Riley, Module 7: Modeling Smokestack Plumes in Cancer Alley, Louisiana Pennsylvania /New York Campus Compact Consortium, 2006.

[11] Jamie Swift, Jacqueline Davis, Robert Clarke, and Michael Czerny. Getting Started on Social Analysis in Canada, (Fourth Edition). Between the Lines, 248 pages (2003).

[12] Larry Michealsen, "Team Based Learning", Effective Teaching Institute, UNB Saint John, 2012. 